\title{
Stay Put—Undoing Screens and Oceans
}

\section{Ninette Rothmüller ${ }^{1}$}

Published online: 26 June 2020

(C) Springer Nature Switzerland AG 2020

Keywords Covid-19. Pandemic · Family separation · Play · Citizenship · Borders · Cultural identity $\cdot$ Digital border-crossing

\section{Staying Put and Digital Border-Crossing}

For several years my daughter and I, who hold passports representing countries as different as you wish to imagine them to be, were advised to 'stay put': to not cross any border together. Officials feared that I would not be able to reenter the country that had entitled my daughter to hold its citizenship. My home-country had denied citizenship to her. Ever since, it's hard to think of my home-country as my motherland.

Staying put; we are experts-I can tell you. We can be everywhere, going nowhere at all. Or as my 7-year-old puts it, 'Easy, Mama, just do it'. There you go, social distancing, just do it! What are the choices anyways? This paper is written by three generations of digital border-crossers; two of whom do not acknowledge this border to be what I think it is: a screened electricity powered interface robbing dialogic encounters of all sensory pleasures. Perhaps, I am wrong; there is always that option.

Covid-19 hits, and we are requested to stay in place. I explain to my 7-year old what this might look like, and she looks at me like, 'So, what's new?' Same with my mother, who although belonging to a risk group, stubbornly declares, 'Ah, life will go on'. I mean, yes, for some of us. As it turns out, for those who are privileged and do not experience intersectional oppression. But then again, 'What's new?'

Since my daughter was born, her almost daily interactions with her transatlantic grandparents have taken place screen-animated. My daughter's grandparents are flat, they never smell or have bad breath, their kisses aren't wet, and they are approximately $28-\mathrm{cm}$ tall, and, seated next to each other, $35-\mathrm{cm}$ wide. If that's too mathematical for you, here's my daughter's explanation: her cat is bigger than her grandparents. Get it?

Ninette Rothmüller

nrothmueller@smith.edu

1 Smith College, Northampton, MA, USA 
Her grandparent's house comes in rectangular flat slices. There seems to be no bathroom, and they always insist on going to bed hours before their grandchild. My daughter is in disbelief that they would even consider going to bed at four o'clock in the afternoon. The rigor of time zones is beyond what she deems herself as having to oblige to.

One can shut my daughter's grandparents off - a feature we have never used, but it provides peace of mind to know that it is there. One can also silence them or turn the volume of their voices down. Or, let us say, as happened earlier this year, Oma ${ }^{1}$ went to the hairdresser — when that was still an option — and my daughter does not like her new hairdo (at all). Well, she can simply disable the video and switch to voice only; hairdo gone. Easy!

Both my mother and my daughter only use a computer when playing with each other. Truly, my mother has no email account and even insists that cell phones are modern-day nonsense. I am with her on the cell phones, yet my concerns regard surveillance, but let us not go there. My daughter has absolutely no interest to ever watch a movie; but wouldn't it be nice if she would from time to time, now that schools are closed and we learn and work in the same space? Movies are not interactive, so what's the big deal? Try a grandmother, they are much better screen entertainment; custom built, responsive - as in, without any button pressed they will pause when you have to run to the toilet and resume from where they were when you come back, providing a short summary of past activities if your bathroom break was too long for you to remember. In short, they are funny on-demand entertainment and most of the time the amusement can be rated 'approved for all ages.'

\section{Intergenerational Encounters-Screens in Action}

OK, let us make this essay an educational piece, shall we? It's Covid-19 time, we need to learn from each other. What you will need to activate a trial version of 'stay put', as we call it, is a local 7-year old (five or six will do as well, younger might expose your computer screen to saliva finger prints) and a transatlantic set of grandparents. One grandparent will do as well, but two are more fun. It is important that you study the personal features of the transatlantic grandparents that you might have had to recruit or received when purchasing this trial version. At this point in time, during Covid-19, recruitment is not a problem; grandparents are out there, and they are as socially hungry as your local 7-year old might be.

In our case, Oma never touches the computer; she will not even plug it into a power source when its battery starts to run low. Touch would acknowledge the computer's existence; would acknowledge that we are playing a computer game, and that's a nogo. You will, across the ocean, be responsible for all troubleshooting. That is all the generation in-between is needed for. Your input will never be regarded in any other way.

Also, you might have ended up with an $\mathrm{Opa}^{2}$ whose features include widely animated moving and clicking of the mouse - all the time, except when it's needed.

\footnotetext{
${ }^{1}$ Oma is the informal name for grandmother in German.

${ }^{2}$ Opa is the informal name for grandfather in German.
} 
Here's what I recommend. If the grandfather or grandmother in your game ends up displaying such features, do not consider changing their profile; it will not happen. Changes never save in grandparents, or 7-year olds for that matter. Instead, I recommend to purchase two big bags of patience and 'stay put'.

With a calm, clear, loving voice repeat the same set of 8-10 sentences over and over again. Additionally, keep any widely animated family member at least one yard away from the computer cord at all times, and during initiating and finishing the video call also away from the computer mouse or touch pad. Never expect grandparents to remember, for example, where the button to disable the video is even if you have said a million times (really) that it looks like a warming bottle. The response will be, 'I have no warming bottle in my computer! What do you mean? What color is it?', the absolutely color-blind grandparent might add. So, never mind, just roll with it.

If you manage to, you are in for a treat, I promise. What you will witness is kind-of magic. And magic, we adults - academics in particular - do not witness often. One last thing, the only thing that you might want to emphasize with your 7-year old is that under no circumstances is the computer cord ever to be used as jumping rope; never that is.

Which brings me to the free-style version of this game. Rules generally do disenable stay put's most famous feature: phantasy. Or as my daughter recently told her Oma with a stern face, 'We don't have rules'. Ehm, I think, we don't? Here we are, first we cannot leave the country and now we cannot even leave the house, but apparently rules do not apply to us. If you can get yourself to this mindset, you will fly. I promise.

\section{Family Separation-Special Features and Extended Selves}

There are several invisible figures that are extra features that can be activated at any given point in time during this game. For developmental reasons-yes, sorry, I am a social worker - it is very important for the emotional development of your potentially displaced and spatially restricted child that these figures remain the same for long periods of time; years that is. This also helps with grandparents who display memory that frequently differs from what you remember. Continuity helps. Incorporating comforting rituals to your child's screen-exposed life will help the development of trust and enhance the feeling of emotional safety.

In our case, Opa can activate and seamlessly transform into two figures. One is an ambulance driver, called ambulance driver, who never finds the hospital, drives like a mad head, and seems to generally not know much about the key components of his job description. The second figure is a boy called Max. Max is 3 years old, never grows any older. The only thing that he is really good at is doing complete nonsense. Max reminds my mother and me of Opa, but that's another story altogether. Let me just say that family histories can nicely be worked through using extended selves, such as Max.

Max is loud, likes to dig for boogers and gets my daughter from tears to giggles in a split second. Oma effortlessly can transform into various figures, and without demand, Oma senses when which figure needs activating. Her figures include two horses, one reasonable and one not, several nurses and a medical doctor. Because currently, you see, since the outbreak of Covid-19, my daughter and she run a children's hospital, of which my mother says, 'It is important that we now run a children's hospital, where life 
is good and where one does not need to be scared. There in our hospital Dr. Pacifier, and nurse Sniffy, who are both very funny and medically skilled, take care of everyone and all like to be there.'

My daughter and my mother own identical Playmobil figures that they pass through the screen, effortlessly. The person passing towards the other letting the figure smoothly disappears into her sleeve, like a magician. The person receiving opening her fist to let the figure appears. They also have an identical card set, and while playing looks logistically demanding from the outside, it must be my lack of phantasy that limits my understanding of how they use the cards. They seem to have the best time of their lives.

Remember, no rules apply; well that's the only rule. They build cruise ships with Legos; one the main ship, the other the dinghy and then they sail the ocean that divides them. Easy! When my mother says, 'Oh, look there's a storm coming', my daughter will look out of her window, confirming that indeed she can see the dark clouds. Twothirds of the time during her videocalls with her grandparents, my daughter's gaze is not directed to the screen, but towards the objects the (joint) activity is conducted with, Lego blocks, pens and paper, Playmobil figures, and so on.

I recently asked her where Oma is. She looked at me with the disbelief that 7-year old faces can display. 'Oma is sitting on my chair,' she explained, speaking slowly, to make sure that I get it. Oma, so I had thought, was instead sitting on her chair across the ocean, and it had been the computer that balanced on my daughter's chair. Never, mind, I must be wrong, as also my parents insisted that they are sitting in my daughter's room.

Citizenship, borders, cultural identity, oppressed language preferences, social isolation, identity politics, surveillance, and inequality, all continue to matter deeply as their explosive force is heightened by the Covid-19 pandemic and the intersectional disadvantages it increases and/or pushes into visibility. My daughter and her grandparents are off to la-la-land some might say. This might be so, but as they are, they have discovered how to comfort each other during times of crisis and during a long-term geographical separation enforced upon them. They have learned how to be with each other despite all odds. They know how to share precious resources, and they provide each other with agency, disregarding ageism or patronizing. They display tolerance towards Max, who will not ever act reasonable and still, he can trust to be a loved member of their virtual family.

We will need the phantasy of everyone to imagine futures possible after Covid-19 (Carr 2020; Jandrić 2020). Welcoming ideas, non-judgmental. Many of the rules that applied in the past will not apply anymore, and we will have to find ways to live with and for each other, from here. For all academics among us, who prefer words, philosopher Paul B. Preciado's postscript 'Vom Virus Lernen' (learning from the virus) can guide such contemplations (Preciado 2020). However, watching children play with Playmobil figures will do as well. I have learned a lot about humanity during my studies. I have learned more by watching my daughter and my parents play with each other undoing an ocean. They are privileged to have this opportunity and what they make out of it radiates out, socially.

The other night, as we went to bed, my daughter whispered, 'Oma smelled so good today'. 'Really?', I asked confused. 'Yes,' my daughter sighs. Ah, damn it, I think, I have just submitted a paper stating that Omas displayed on computer screens never smell. What was I thinking? 
Acknowledgements I thank Petar Jandrić and Sarah Hayes for providing their feedback. I am deeply grateful to my parents and my daughter, for undoing an ocean and for making me laugh in tears as I conducted the research for this article. I extend my gratitude to Bonnie Katusich for copyediting this article.

\section{References}

Carr, P. R. (2020). If everything has changed, why such a focus on bailing out capitalism? The somber reality underpinning Covid-19. Postdigital Science and Education. https://doi.org/10.1007/s42438-020-00115-6. Jandrić, P. (2020). Postdigital research in the time of Covid-19. Postdigital Science and Education, 2(2), 233238. https://doi.org/10.1007/s42438-020-00113-8.

Preciado, P. B. (2020). Ein Apartment auf dem Uranus - Chroniken eines Übergangs. Berlin: Suhrkamp Verlag. 